\title{
Technical update on transcatheter arterial chemoembolization
}

\author{
Sapna Puppala \\ Department of Radiology, Leeds Teaching Hospital, Leeds LS1 3EX, UK.
}

Correspondence to: Dr. Sapna Puppala, Consultant vascular interventional radiologist, Leeds Teaching Hospital NHS Trust, Great George street Leeds, Leeds LS13EX, UK. E-mail: puppalasapna@hotmail.com

How to cite this article: Puppala S. Technical update on transcatheter arterial chemoembolization. Hepatoma Res 2019;5:44. http://dx.doi.org/10.20517/2394-5079.2019.28

Received: 5 Nov 2019 First Decision: 2 Dec 2019 Revised: 12 Dec 2019 Accepted: 16 Dec 2019 Published: 31 Dec 2019

Science Editor: Dalbir Sandhu Copy Editor: Jing-Wen Zhang Production Editor: Jing Yu

\begin{abstract}
Transcatheter arterial chemoembolization has become an established drug delivery system for palliative or bridging treatment of hepatocellular carcinoma. Over the last two decades, various research and developments have taken place to improve the transcatheter arterial chemoembolization procedure from both a clinical and a technical perspective. This review article aims to provide an update on the technical developments over the last decade.
\end{abstract}

Keywords: Transcatheter arterial chemoembolization, Doxorubicin, bead, cisplatin

\section{INTRODUCTION}

Since its first introduction in the late 1970s, transcatheter arterial chemoembolization (TACE) has become an established drug delivery system for palliative or bridging treatment of hepatocellular carcinoma $(\mathrm{HCC})^{[1,2]}$. Randomized controlled trials have shown a survival benefit in patients treated with TACE, compared to transcatheter arterial embolization (TAE) using bland agents with no additional chemotherapy ${ }^{[3-5]}$. TACE has also replaced trans-arterial chemotherapy (TAC), which delivered chemotherapy in isolation without vessel occlusion.

The liver has a dual blood supply via both the hepatic artery and the portal vein; TACE takes advantage of this dual blood supply. As $80 \%-90 \%$ of HCCs derive their blood supply from the hepatic artery, it therefore, becomes an ideal vessel to access and deliver both an embolic and a chemotherapeutic agent,

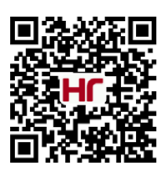




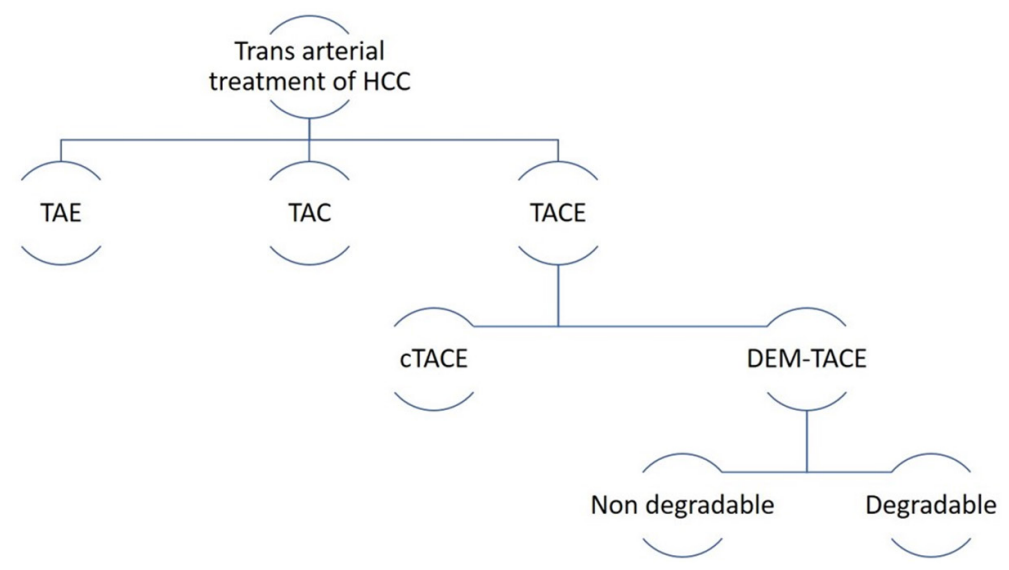

Figure 1. A simplified classification of various transarterial image-guided treatment options for HCC. TAE is a bland embolization that is rarely used unless in an emergency for treating ruptured HCC. TAC is currently not used. TACE is the most commonly used technique with cisplatin or doxorubicin. HCC: hepatocellular carcinoma; TAE: transarterial embolization; TAC: transarterial chemotherapy; TACE: transcatheter arterial chemoembolization; CTACE: conventional transcatheter arterial chemoembolization; DEM-TACE: drug-eluting microsphere-transcatheter arterial chemoembolization

leading to tumor ischemia, necrosis, and growth control ${ }^{[6]}$. As most normal hepatocytes are supplied by the portal vein, embolizing via the hepatic artery minimizes collateral ischemic damage and reduction in liver function, and the chemotherapy agent is not affected by the first-pass metabolism, as it would be if administered orally or intravenously.

TACE can be technically classified as conventional (cTACE), which can be selective or less than selective, and drug-eluting microsphere (DEM-TACE), where the treatment is delivered as close to the tumor as possible by super-selective catheterization of the feeding arteries. DEM-TACE can be further subdivided based on the degradable nature of the microsphere [Figure 1].

cTACE is undertaken with lipiodol, a poppy seed oil-based contrast medium, causing transient ischemia, in which chemotherapy agents such as cisplatin, doxorubicin, or mitomycin are suspended as an emulsion. Due to the lack of Kupffer cells in the tumor, lipiodol has the benefit of being retained in the tumor for weeks, thus enabling post-procedural computed tomography (CT) evaluation of the tumor load. However, lipiodol can lead to severe pain requiring strong opioid analgesia. cTACE lacks the benefit of a sustained high drug level in the tumor and can also lead to systemic elevation of the drug levels. Post-embolization syndrome is more common with $\mathrm{CTACE}^{[7,8]}$. Due to the above disadvantages, DEM-TACE was introduced in 2006, which produced sustained tumor-selective drug delivery, limited systemic elevation of drug levels, and permanent feeding vessel embolization ${ }^{[9]}$. Fewer courses of TACE are required with DEM-TACE compared to $\mathrm{CTACE}^{[10]}$. There is no Level 1 evidence demonstrating superiority in efficacy between the two techniques; however, there are many single-center prospective cohort studies demonstrating a higher complete response and lower rate of progressive disease with DEM-TACE ${ }^{[11]}$.

\section{CURRENT INDICATIONS AND PATIENT SELECTION}

Patient selection for TACE continues to depend on the tumor size, number, extrahepatic spread, liver function, portal vein involvement, and the patient's general performance status. Childs-Pugh score and Barcelona clinic liver criteria are used to select patients for the appropriate treatment ${ }^{[12]}$. A multidisciplinary team approach to consider a patient for TACE and pre-procedure patient counseling are important to ensure ideal patient selection. Table 1 summarizes the indications for TACE. Decompensated liver function, infiltrative HCC, untreatable AV fistula, renal dysfunction, and chemotherapy-related 


\section{Table 1. Indications for transcatheter arterial chemoembolization}

Intermediate stage patients, BCLC-B (asymptomatic, multinodular tumors without vascular invasion or extrahepatic spread)

Patients tumor suitable for curative treatment but not eligible due to performance status

Disease recurrence after curative treatment by surgery or ablation

Bridging or downstaging while patient fulfills criteria for liver transplantation or donor becomes available

Downsizing tumor or reducing circulation to meet criteria for ablation

BCLC: barcelona clinic liver cancer
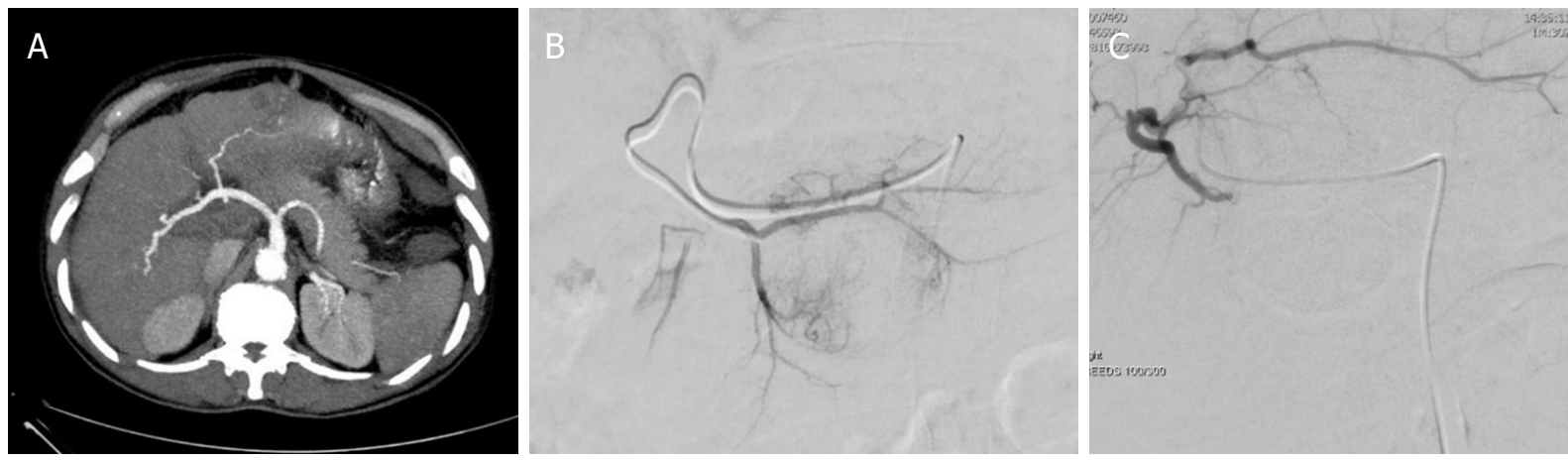

Figure 2. A: an oblique axial CTA multiple intensity projections reformat, showing the vascular path from the coeliac axis to the left lobe tumor; B, C: intraprocedural images pre- and post-embolization. Given the prior delineation of vascular anatomy, only two arterial angiograms were done, reducing contrast load and radiation exposure

contraindication are absolute contraindications. HCC size above $10 \mathrm{~cm}$, portal hypertension with or without untreated varices, portal vein thrombosis, and biliary involvement are relative contraindications. The more infiltrative the tumor is into the vessels and bile ducts, the higher is the risk of complications. Cardiac failure is a contraindication for cTACE but not for DEM-TACE.

\section{TACE and liver transplantation}

Unlike TACE, liver transplantation is curative in a select group of patients with HCC. TACE can be used as a bridging treatment to inhibit tumor progression in patients who are candidates for transplant while awaiting a suitable donor or fulfillment of transplant criteria ${ }^{[13,14]}$.

\section{TACE as an adjunct to other therapies}

Increasingly, TACE is being used as an adjunct to reduce tumor size and vascularity to facilitate ablation techniques, such as radiofrequency, microwave, and cryotherapy. These ablation techniques can also be used after TACE for residual disease even if a patient was originally deemed suitable only for TACE ${ }^{[15-17]}$.

\section{PRE-PROCEDURE PATIENT MANAGEMENT}

The preparation of a patient for TACE includes high-quality triple-phase post-contrast CT or magnetic resonance imaging to delineate the arterial anatomy and circulation to the tumor [Figure 2]. Besides, $4 \mathrm{D}$ CT can help reduce intra procedural volume of contrast and risk of nephrotoxicity. CIN (contrast-induced nephrotoxicity) is more common in larger tumors measuring above $5 \mathrm{~cm}$ in size ${ }^{[18-20]}$.

A review of the patient by the operator ahead of the procedure ensures the patient is being informed of the palliative, curative, or bridging nature of the procedure and its complications. For example, accidental damage to the main hepatic artery during TACE is a rare risk, which can make transplant challenging and rarely impossible. 


\section{Established microspheres}

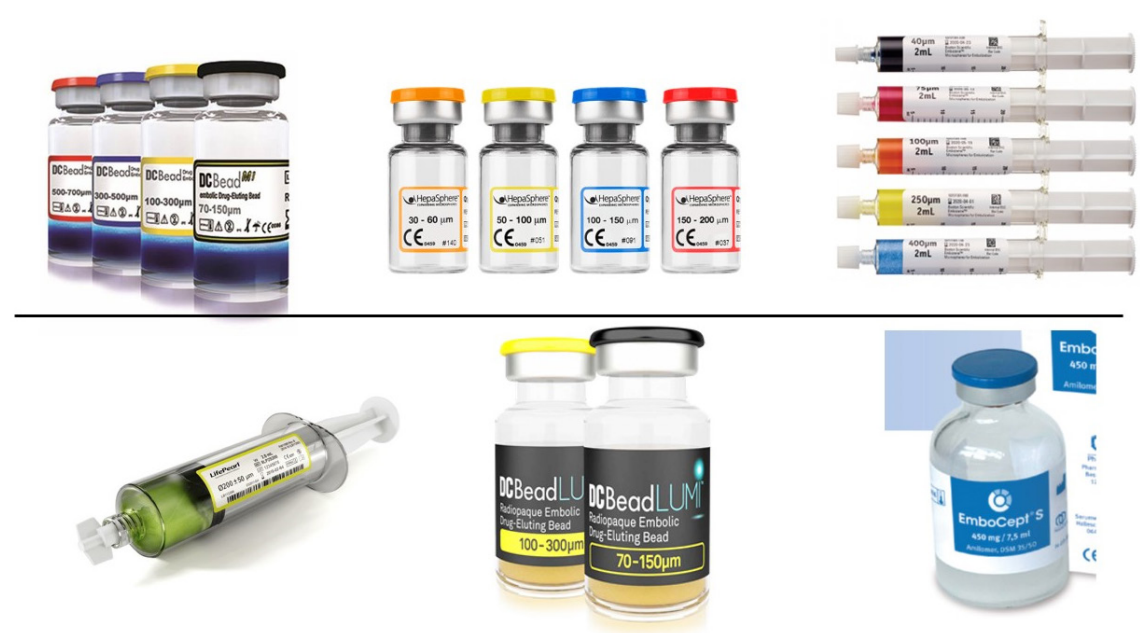

Newer microspheres

Figure 3. The top row shows the established spheres. The bottom row shows the newer spheres currently coming into clinical use. Image courtesy of Biocompatibles UK Limited, Merit Medical USA and Terumo UK. Images of Embozene and Embocept obtained from free brochures on the Internet

Before the procedure, patients should be well hydrated. This is to reduce the risk of nephrotoxicity from iodinated contrast medium, tumor lysis syndrome, and dehydration due to a lack of fluid intake from post-procedure nausea or vomiting ${ }^{[1,20]}$. Due to the risk of infection and abscess formation, antibiotics for prophylaxis is a routine practice based on the local departmental or hospital rules ${ }^{[2,22]}$. Antibiotics, when used, should cover both Gram-positive, Gram-negative and anaerobic organisms and are recommended for all high-risk patient groups such as diabetics, immunosuppressed, etc. A mandatory up to date liver function test should be performed within a week of the TACE given the risk of liver ischemia and failure from the procedure. An echocardiogram of the heart is performed to assess the left ventricular function and to facilitate both patient selection and assess the impact of cytotoxins on the myocardium, especially if multiple episodes of treatment are being considered.

\section{CHEMOTHERAPY AND EMBOLIC AGENTS UPDATE}

\section{Chemotherapy agents}

Cisplatin and doxorubicin remain the routinely used chemotherapy agents for HCC. Other agents such as epirubicin and combinations have been tried with limited advantage ${ }^{[23,24]}$.

\section{Embolic agents}

cTACE

Lipiodol is the agent used for cTACE. Lipiodol has a limited embolic property and causes transient ischemia. Further bland embolization with gel foam or Polyvinyl alcohol (PVA) is used to bring arterial flow to stasis. There has been no further development and a clinical alternative to lipiodol is not available. Cisplatin and doxorubicin are the routine chemotherapy agents used with lipiodol.

\section{DEM-TACE}

DEM-TACE uses a drug-eluting microsphere as embolic agents. The various spheres available and their advantages are listed in Table 2 and depicted in Figure 3. DC bead, HepaSphere, and Embozenes are polyvinyl alcohol-based. Life pearl is polyethylene glycol-based. 
Table 2. Various drug-eluting microspheres currently available in the market and their advantages

\begin{tabular}{|c|c|c|c|c|}
\hline Types & Company & Structure & Available sizes $(\mu \mathrm{m})$ & Advantages \\
\hline $\begin{array}{l}\text { DC Bead (EU) } \\
\text { LC Bead (USA) } \\
\text { M1 version is smaller } \\
\text { size }\end{array}$ & $\begin{array}{l}\text { BTG, London, } \\
\text { UK (Now Boston } \\
\text { Scientific) }\end{array}$ & $\begin{array}{l}\text { Polyvinyl alcohol hydrogel } \\
\text { modified with sulfonate } \\
\text { groups }\end{array}$ & $\begin{array}{l}70-150 \\
100-300 \\
300-500 \\
500-700\end{array}$ & $\begin{array}{l}\text { Largest data available, can be } \\
\text { loaded before embolization and } \\
\text { as a secondary action, will elute a } \\
\text { local, controlled and sustained dose } \\
\text { to the tumor after embolization }\end{array}$ \\
\hline DC bead LUMI & $\begin{array}{l}\text { BTG, London, } \\
\text { UK (Now Boston } \\
\text { Scientific) }\end{array}$ & $\begin{array}{l}\text { As above and also, covalently } \\
\text { bound radio-opaque moiety }\end{array}$ & $\begin{array}{l}70-150 \\
100-300\end{array}$ & $\begin{array}{l}\text { Visibility on fluoroscopy } \\
\text { and on table cone-beam CT }\end{array}$ \\
\hline $\begin{array}{l}\text { HepaSphere or } \\
\text { QuadraSphere }\end{array}$ & $\begin{array}{l}\text { Merit Medical, } \\
\text { South Jordan, UT, USA }\end{array}$ & $\begin{array}{l}\text { Poly (vinyl alcohol-co- } \\
\text { sodium acrylate) hydrogel }\end{array}$ & $\begin{array}{l}\text { Dry state } \\
30-60 \\
50-100 \\
100-150 \\
\text { Hydrated state } \\
120-240 \\
200-400 \\
400-600 \\
600-800\end{array}$ & $\begin{array}{l}\text { Compresses by } 80 \% \text { but } \\
\text { returns to shape and size } \\
\text { becoming predictable and } \\
\text { conformable. } \\
\text { Entire sphere loads }\end{array}$ \\
\hline $\begin{array}{l}\text { Embozene TANDEM } \\
\text { Oncozene }\end{array}$ & $\begin{array}{l}\text { Varian Medical } \\
\text { Systems, Inc. } \\
3100 \text { Hansen Way, } \\
\text { USA }\end{array}$ & $\begin{array}{l}\text { Hydrogel core made of } \\
\text { sodium poly (methacrylate) } \\
\text { and outer biocompatible } \\
\text { shell of poly bis } \\
\text { [trifluoroethoxy] } \\
\text { phosphazene }\end{array}$ & $\begin{array}{l}\text { Oncozene } \\
40 \pm 10 \\
75 \pm 15 \\
100 \pm 25 \\
\text { Embozene } \\
40- \\
75 \\
100 \\
250 \\
400 \\
500 \\
700 \\
900\end{array}$ & $\begin{array}{l}\text { Tightly calibrated to enable more } \\
\text { choices for embolization. } \\
\text { Less than } 5 \% \text { size change on } \\
\text { eluting }\end{array}$ \\
\hline LifePearl & $\begin{array}{l}\text { Terumo European } \\
\text { Interventional } \\
\text { Systems, Leuven, } \\
\text { Belgium }\end{array}$ & $\begin{array}{l}\text { Hydrogel network of } \\
\text { poly ethylene glycol and } \\
\text { 3-sulfopropyl acrylate }\end{array}$ & $\begin{array}{l}100 \pm 25 \\
200 \pm 50 \\
400 \pm 50\end{array}$ & $\begin{array}{l}\text { Wide range of drug loading options } \\
\text { Enhanced suspension } \\
\text { characteristic. } \\
\text { Tight calibration and longer } \\
\text { suspension time }\end{array}$ \\
\hline $\begin{array}{l}\text { DSM - TACE } \\
\text { EMBOCEPTC }\end{array}$ & $\begin{array}{l}\text { PharmaCept GmbH, } \\
\text { Berlin, Germany }\end{array}$ & $\begin{array}{l}\text { Active ingredient - Amilomer } \\
\text { DSM 35/50. Partly } \\
\text { hydrolyzed starch, cross- } \\
\text { linked and substituted with } \\
\text { glycerol ether groups }\end{array}$ & 50 & $\begin{array}{l}\text { Biodegradable. } \\
\text { Tolerated better as less post } \\
\text { embolization syndrome. } \\
\text { Nonimmunogenic }\end{array}$ \\
\hline
\end{tabular}

CT: computed tomography; DSM: degradable starch microsphere; TACE: transcatheter arterial chemoembolization

These microspheres or beads are available in various sizes. A very small size bead usage in a large HCC stands the risk of shunting. Large size bead, on the other hand, can cause proximal occlusion without enough beads reaching the middle of the tumor. The size of the microsphere should be chosen based on tumor circulation ${ }^{[25,26]}$. Routinely, a non-degradable DC bead at $100-300 \mu \mathrm{m}$ is our preferred size, which shrinks by $20 \%$ upon standing.

\section{DC bead}

Consists of polymeric microspheres with the ability to encapsulate chemotherapeutic agents such as doxorubicin, irinotecan, and epirubicin with hydrogen ions, by electron attraction. It is manufactured by free radical polymerization of PVA with modification of sulfonate sodium to enable it to encapsulate the chemotherapeutic agent. DC beads have the most available clinical data and provide a sustained release of the drug. Patients with DC bead DEM-TACE treatments can receive a higher dose of doxorubicin without the undesired systematic circulation of injected drugs in comparison with CTACE $^{[27]}$. Ninety percent of patients with unresectable HCC receiving DEM-TACE do not have hepatic artery damage with one- and two-year survival rates around $70 \%$ and $60 \%$, respectively ${ }^{[23]}$. 

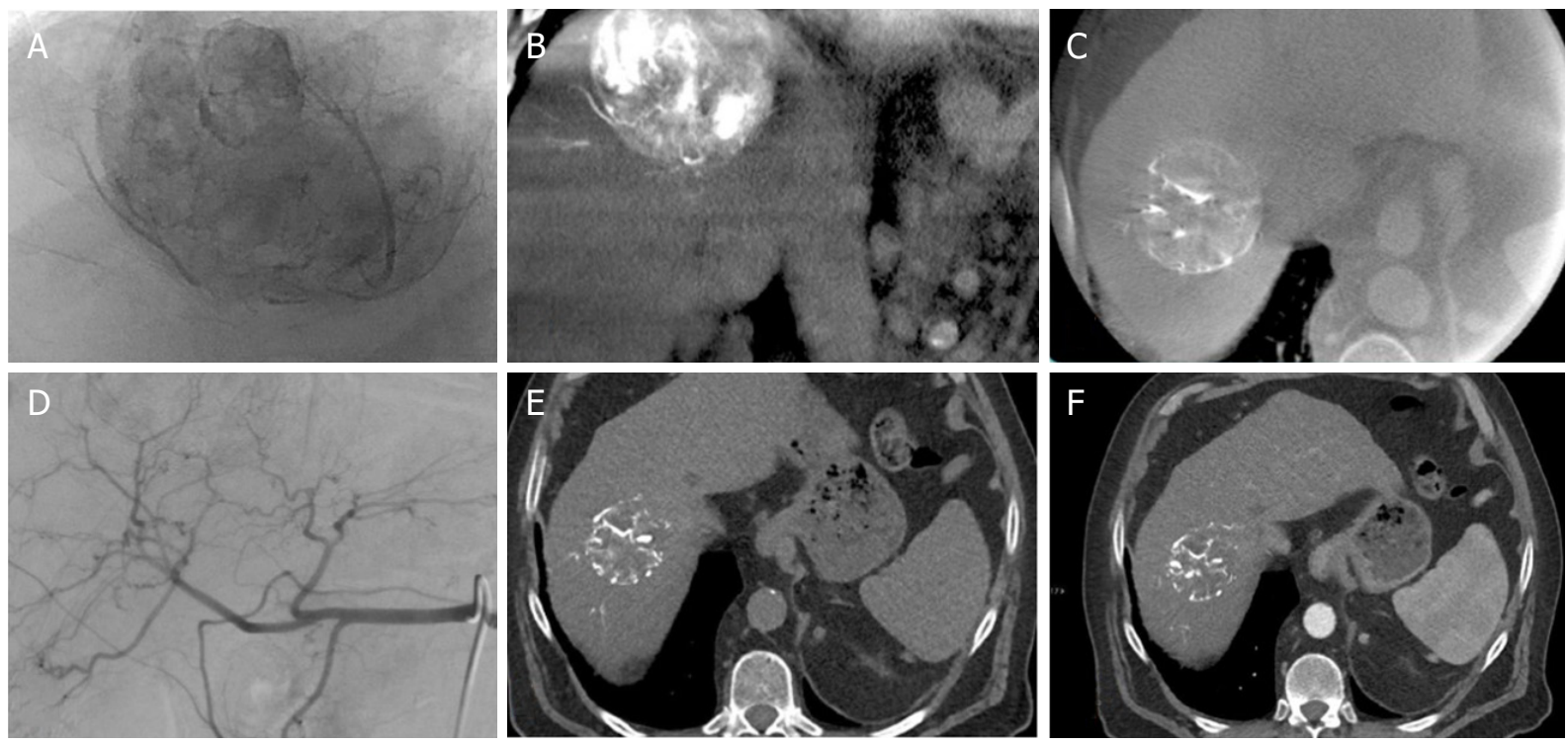

Figure 4. A-C: fluoroscopy and non-contrast CBCT immediately and first LUMI-TACE demonstrate excellent uptake within the lesion with minimal non-target embolization; D: second LUMI-TACE Angiography showing feeding vessels supplying small areas of residual disease; E, F: unenhanced and arterial-phase axial computed tomography images one month following the second LUMI-TACE, demonstrating a complete response. Comparison with the unenhanced imaging is vital. Image curtesy of Dr. Peter Littler - consultant interventional radiologist, Freeman Hospital, Newcastle upon Tyne, UK

\section{HepaSpheres or QuadraSphere}

These microspheres are hydrophilic, calibrated, and can be compressed by $80 \%$, facilitating a smooth transit in a microcatheter. They are small, soft, and easily conform to the vessel lumen for complete occlusion, enabling greater tumor necrosis ${ }^{[28,29]}$.

\section{LifePearl}

LifePearl is made from polyethylene glycol unlike the preceding three microspheres, which are made from polyvinyl alcohol. Polyethylene glycol offers a longer time in suspension than DC Bead and HepaSphere when loaded with doxorubicin and DC Bead and Tandem when loaded with irinotecan. Longer time in suspension enables a smoother embolization procedure without the need for any interruption to resuspend the microspheres ${ }^{[30]}$.

\section{Radio-opaque microspheres - DC or LC bead LUMI}

Classically, the microspheres or beads, after loading with the chemotherapy agent, are mixed with nonionic contrast for direct fluoroscopic visualization. These beads do not retain contrast in tumor vessels and are washed out within minutes of the procedure. DC or LC Bead LUMI ${ }^{\mathrm{TM}}$ microspheres contain covalently bound iodine making them radio-opaque and enabling real-time assessment of the bead deposition in the HCC. The density and distribution of the radio-opaque beads can help accurately identify the embolization endpoint and the degree of flow stasis. Additionally, one can also visualize non-target reflux. Performing an on-table cone-beam non-contrast enhanced CT scan, immediately after embolization with LUMI beads, may provide important information about the completeness of treatment based on contrast retention ${ }^{[31]}$. During follow up imaging, it is essential to compare unenhanced with contrast-enhanced CT images to ensure accurate assessment of response, as shown in Figure 4.

\section{Degradable starch microsphere-TACE}

Degradable starch microsphere (DSM) has an active ingredient called Amilomer, DSM 35/50. The starch microspheres are derived from partly hydrolyzed starch, which is cross-linked and substituted with 


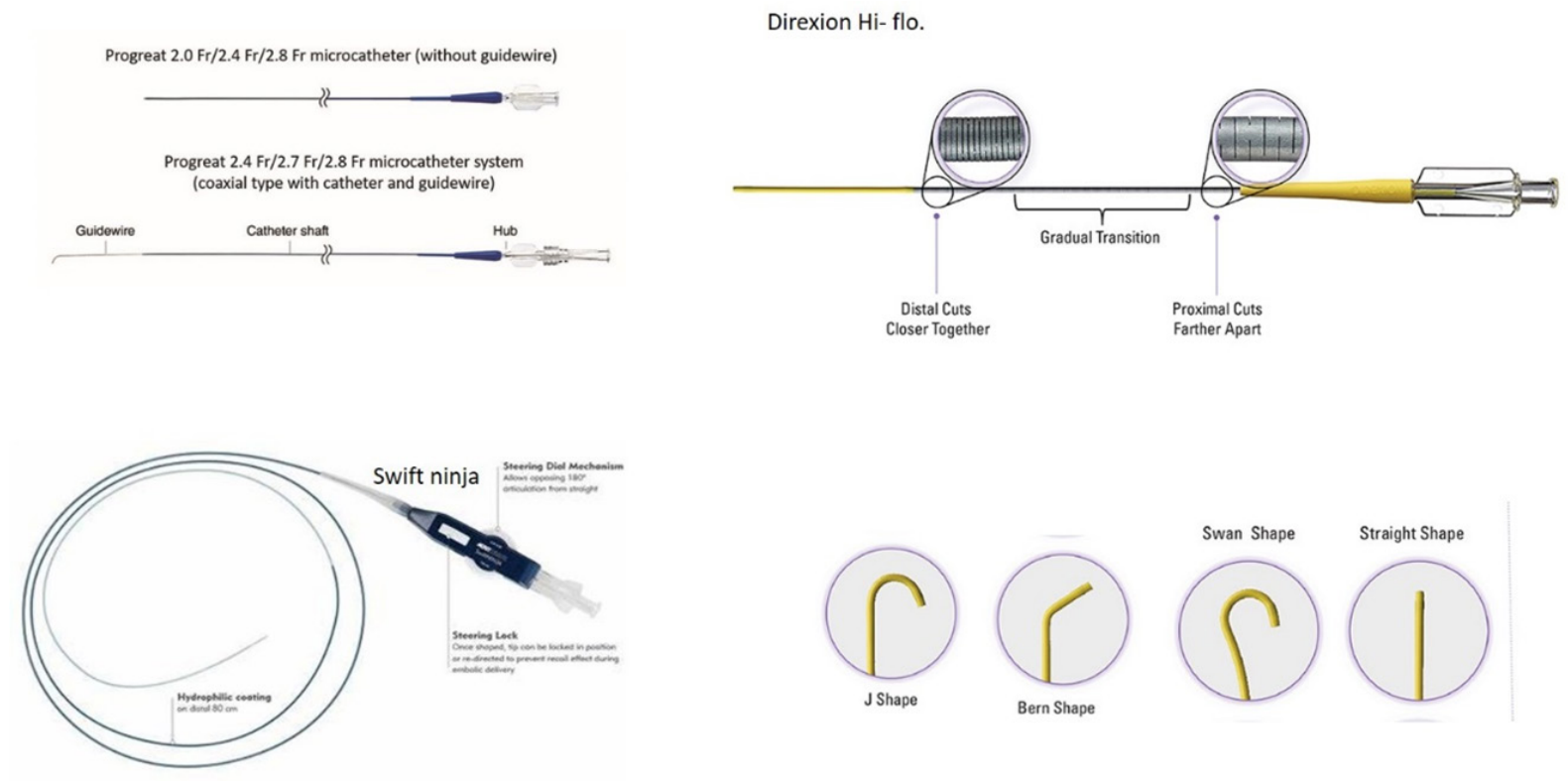

Figure 5. Various microcatheters with advanced properties such as coaxial wires, shapes, torque ability, and steerability. Image courtesy of Pro great - Terumo UK, Direxion Boston Scientific UK, Swift Ninja Merit Medical USA

glycerol ether groups. The microsphere is non-immunogenic and is prepared in a highly pure form of starch, which undergoes enzymatic degradation by $\alpha$-amylase. The degraded material is completely watersoluble. The DSM sphere is small at $50 \mu \mathrm{m}$ with a half-life of $35 \mathrm{~min}$. There is reduced post-embolization syndrome with less pain and ischemic damage to the tumor-bearing organ. This makes it ideal for large tumors enabling therapeutic benefits for patients with repeated cycles and better tolerance ${ }^{[32,33]}$.

\section{NEWER INTRAPROCEDURAL ACCESSORIES}

\section{Interventional kit}

Compared to the 1980s and 1990s, super-selective catheterization techniques and catheter skills have evolved and become a routine for various transcatheter procedures. Selective catheterization with microcatheters is routine, with the use of a 2.7 French and 2.4 French micro-catheter. More recently, 2.0 French, angled and steerable micro-catheters with or without coaxial wire systems have become readily available. As shown in Figure 5. Novel techniques of catheterization have also evolved such as side hole access via a balloon occlusion catheter ${ }^{[34,35]}$.

\section{On-table CT}

Development of the hybrid CT/angiography system and C-arm cone-beam CT technology provides crosssectional imaging as an adjunct to catheter angiography with or without intra-arterial contrast. This can be used with image fusion or co-registration with catheter angiogram to help localize and perform selective $\mathrm{TACE}^{[36-38]}$.

The LUMI beads are radio-opaque, enabling fluoroscopic visualization of bead deposition in the tumor, and are ideally suited to be visualized on the cone-beam on-table CT to assess for endpoints and plan further courses of $\mathrm{TACE}^{[31]}$.

\section{Radial access TACE}

This approach is gaining popularity as an option for patients to choose between femoral and radial access, as shown in Figure 6. In the past, radial and brachial access TACE were used as alternative access sites in 

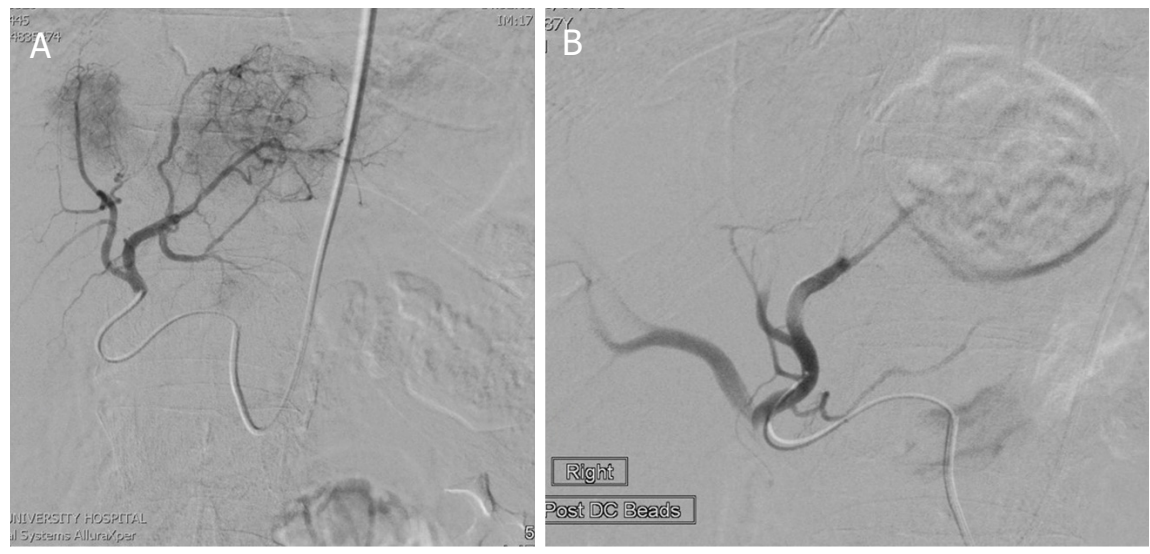

Figure 6. Catheter angiogram before (A) and after (B) transcatheter arterial chemoembolization performed via radial access due to steep downward angulation of the coeliac axis and upward of the hepatic artery

patients with a steeply angled coeliac axis, challenging or occluded iliac and femoral arteries, or due to an unstable catheter position via the femoral access.

More recently, the benefits of early mobilization and superior patient satisfaction via radial artery access have made radial access a routine rather than an alternative ${ }^{[39]}$. Radial access has been studied extensively for coronary intervention with additional benefits in an acute setting ${ }^{[40]}$. The medical device industry also responded by developing longer shaft length catheter systems to reach the tumors in the liver ${ }^{[41]}$. A small risk of posterior fossa stroke and hand ischemia exists, and this should be clearly explained to the patients as part of the informed consent. A Barbeau test is a modification of Allen's test and is a requirement to ensure enough collateral flow via the ulnar artery to the hand. Vasodilators are used to prevent spasm of the radial artery but can be beneficial in the hepatic circulation during catheter manipulation.

\section{COMPLICATIONS}

The incidence of post-TACE complications is unchanged and liver ischemia; infarction and failure continue to be the major risks. However, in comparison to CTACE, the severity of post-embolization syndrome can be less with DEM-TACE due to the highly selective technique of embolization. The newer starch microspheres (DSM-TACE) are biodegradable and better-tolerated, making them ideal in unresectable large HCCs and patients requiring multiple episodes of TACE.

\section{CONCLUSION}

TACE continues to be an important treatment option to improve survival for a chosen group of patients with HCC who are unsuitable for other modern image-guided techniques or are unfit for surgery. It is largely a palliative procedure and to a lesser extent curative. The advances in catheters, embolic technology, and catheter skills over the last two decades have made it a safe, effective, and well-tolerated procedure. Standardization of type of TACE, size of bead, and the type and volume of a chemotherapy agent is not yet available. Magnetic nanoparticle as a carrier is ongoing research ${ }^{[42]}$.

\section{DECLARATIONS}

\section{Authors' contributions}

The author contributed solely to the article.

\section{Availability of data and materials}

Not applicable. 


\section{Financial support and sponsorship}

None.

\section{Conflicts of interest}

The author declared that there are no conflicts of interest.

\section{Ethical approval and consent to participate}

Not applicable.

\section{Consent for publication}

Not applicable.

\section{Copyright}

(c) The Author(s) 2019.

\section{REFERENCES}

1. Guan YS, He Q, Wang MQ. Transcatheter arterial chemoembolization: history for more than 30 years. ISRN Gastroenterol 2012;2012:480650.

2. Friedman MA, Volberding PA, Cassidy MJ. Therapy for hepatocellular cancer with intrahepatic arterial adriamycin and 5-fluorouracil combined with whole-liver irradiadiation: a Northern California Oncology Group study. Cancer Treat Rep 1979;63:1885-8.

3. Lammer J, Malagari K, Vogl T, Pilleul F, Denys A, et al. Prospective randomized study of doxorubicin-eluting-bead embolization in the treatment of hepatocellular carcinoma: results of the PRECISION V study. Cardiovasc Intervent Radiol 2010;33:41-52.

4. Llovet JM, Bruix J. Systematic review of randomized trials for unresectable hepatocellular carcinoma: chemoembolisation improves survival. Hepatology 2003;37:429-42.

5. Puppala S, Patel R, Yap KS, Patel J, Wah T, et al. Hepatocellular carcinoma: modern image-guided therapies. Postgrad Med J 2016;92:165-71.

6. Raoul JL, Heresbach D, Bretagne JF, Ferrer DB, Duvauferrier R, et al. Chemoembolisation of hepatocellular carcinomas. A study of the biodistribution and pharmacokinetics of doxorubicin. Cancer 1992;70:585-90.

7. Kang YJ, Lee BC, Kim JK, Yim NY, Kim HO, et al. Conventional versus small doxorubicin-eluting bead transcatheter arterial chemoembolization for treating barcelona clinic liver cancer stage 0/A hepatocellular carcinoma. Cardiovasc Intervent Radiol 2019; Epub ahead of print [PMID: 31646378 DOI: 10.1007/s00270-019-02349-9]

8. Puppala S. Management of Post-embolization Syndrome. In: Kessel D, Ray C, editors. Transcatheter Embolization and Therapy. Techniques in Interventional Radiology. Springer: London; 2010.

9. Zou JH, Zhang L, Ren ZG, Ye SL. Efficacy and safety of cTACE versus DEB-TACE in patients with hepatocellular carcinoma: a metaanalysis. J Dig Dis 2016;17:510-7.

10. Kloeckner R, Weinmann A, Prinz F, Pinto dos Santos D, Ruckes C, et al. Conventional transarterial chemoembolization versus drugeluting bead transarterial chemoembolization for the treatment of hepatocellular carcinoma. BMC Cancer 2015;15:465.

11. Li H, Wu F, Duan M, Zhang G. Drug-eluting bead transarterial chemoembolization (TACE) vs conventional TACE in treating hepatocellular carcinoma patients with multiple conventional TACE treatments history: a comparison of efficacy and safety. Medicine (Baltimore) 2019;98:e15314.

12. Llovet JM, Bru C, Bruix J. Prognosis of hepatocellular carcinoma: the BCLC staging classification. Semin Liver Dis 1999;19:329-38.

13. Affonso BB, Galastri FL, da Motta Leal Filho JM, Nasser F, Falsarella PM, et al. Long-term outcomes of hepatocellular carcinoma that underwent chemoembolization for bridging or downstaging. World J Gastroenterol 2019;25:5687-701.

14. Decaens T, Roudot-Thoraval F, Bresson-Hadni S, Meyer C, Gugenheim J, et al. Impact of pretransplantation transarterial chemoembolization on survival and recurrence after liver transplantation for hepatocellular carcinoma. Liver Transpl 2005;11:767-75.

15. Sun Y, Ji S, Ji H, Liu L, Li C. Clinical efficacy analysis of transcatheter arterial chemoembolization (TACE) combined with radiofrequency ablation (RFA) in primary liver cancer and recurrent liver cancer. J BUON 2019;24:1402-7.

16. Shi F, Wu M, Lian SS, Mo ZQ, Gou Q, et al. Radiofrequency ablation following downstaging of hepatocellular carcinoma by using transarterial chemoembolization: long-term outcomes. Radiology 2019;293:707-15.

17. Xu Z, Xie H, Zhou L, Chen X, Zheng S. The combination strategy of transarterial chemoembolization and radiofrequency ablation or microwave ablation against hepatocellular carcinoma. Anal Cell Pathol (Amst) 2019;2019:8619096.

18. Albrecht MH, Vogl TJ, Wichmann JL, Martin SS, Scholtz JE, et al. Dynamic 4D-CT angiography for guiding transarterial chemoembolization: impact on the reduction of contrast material, operator radiation exposure, catheter consumption, and diagnostic confidence. Rofo 2018;190:513-20.

19. Hayakawa K, Tanikake M, Kirishima T, Yoshinami N, Shintani H, et al. The incidence of contrast-induced nephropathy (CIN) 
following transarterial chemoembolisation (TACE) in patients with hepatocellular carcinoma (HCC). Eur Radiol 2014;24:1105-11.

20. Aoe M, Kanemitsu T, Ohki T, Kishi S, Ogura Y, et al. Incidence and risk factors of contrast-induced nephropathy after transcatheter arterial chemoembolization in hepatocellular carcinoma. Clin Exp Nephrol 2019;23:1141-6.

21. Sun W, Xu F, Li X, Li CR. Case series of liver abscess formation after transcatheter arterial chemoembolization for hepatic tumors. Chin Med J (Engl) 2017;130:1314-9.

22. Fohlen A, Tasu JP, Kobeiter H, Bartoli JM, Pelage JP, et al. Transarterial chemoembolization (TACE) in the management of hepatocellular carcinoma: results of a French national survey on current practices. Diagn Interv Imaging 2018;99:527-35.

23. Seki A, Hori S, Kobayashi K, Narumiya S. Transcatheter arterial chemoembolization with epirubicin-loaded superabsorbent polymer microspheres for 135 hepatocellular carcinoma patients: single-center experience. Cardiovasc Intervent Radiol 2011;34:557-65.

24. Gomes AS, Monteleone PA, Sayre JW, Finn RS, Sadeghi S, et al. Comparison of triple-drug transcatheter arterial chemoembolization (TACE) with single-drug TACE using doxorubicin-eluting beads: long-term survival in 313 patients. AJR Am J Roentgenol 2017;209:722-32.

25. Aliberti C, Carandina R, Lonardi S, Dadduzio V, Vitale A, et al. Transarterial chemoembolization with small drug-eluting beads in patients with hepatocellular carcinoma: experience from a cohort of 421 patients at an Italian Center. J Vasc Interv Radiol 2017;28:1495-502.

26. Richter G, Radeleff B, Stroszczynski C, Pereira P, Helmberger T, et al. Safety and feasibility of chemoembolization with doxorubicinloaded small calibrated microspheres in patients with hepatocellular carcinoma: results of the MIRACLE I prospective multicenter study. Cardiovasc Intervent Radiol 2018;41:587-93.

27. Burrel M, Reig M, Forner A, Barrufet M, de Lope CR, et al. Survival of patients with hepatocellular carcinoma treated by transarterial chemoembolisation (TACE) using Drug Eluting Beads. Implications for clinical practice and trial design. J Hepatol 2012;56:1330-5.

28. Malagari K, Moschouris H, Kiakidis T, Harward S, Kelekis A, et al. Five-years outcome analysis of 142 consecutive hepatocellular carcinoma patients treated with doxorubicin eluting microspheres 30-60 $\mu \mathrm{m}$ : results from a single-centre prospective phase ii trial. Cardiovasc Intervent Radiol 2019;42:1551-62.

29. Malagari K, Pomoni A, Filippiadis D, Kelekis D. Chemoembolization of hepatocellular carcinoma with HepaSphere ${ }^{\mathrm{TM}}$. Hepat Oncol 2015;2:147-57.

30. Gjoreski A, Popova-Jovanovska R, Eftimovska-Rogac I, Vejseli J. Safety profile and efficacy of chemoembolization with doxorubicin - loaded polyethylene glycol microspheres in patients with hepatocellular carcinoma. Open Access Maced J Med Sci 2019;7:742-6.

31. Reicher J, Mafeld S, Priona G, Reeves HL, Manas DM, et al. Early experience of trans-arterial chemo-embolisation for hepatocellular carcinoma with a novel radiopaque bead. Cardiovasc Intervent Radiol 2019;42:1563-70.

32. Orlacchio A, Chegai F, Francioso S, Merolla S, Monti S, et al. Repeated transarterial chemoembolization with degradable starch microspheres (DSMs-TACE) of unresectable hepatocellular carcinoma: a prospective pilot study. Curr Med Imaging Rev 2018;14:63745.

33. Orlacchio A, Chegai F, Roma S, Merolla S, Bosa A, et al. Degradable starch microspheres transarterial chemoembolization (DSMsTACE) in patients with unresectable hepatocellular carcinoma (HCC): long-term results from a single-center 137-patient cohort prospective study. Radiol Med 2019; Epub ahead of print [PMID: 31583558 DOI: 10.1007/s11547-019-01093-x]

34. Meng XX, Liao HQ, Liu HC, Jiang HL, Gu YF, et al. Application of side-hole catheter technique for transradial arterial chemoembolization in patients with hepatocellular carcinoma. Abdom Radiol (NY) 2019;44:3195-9.

35. Hatanaka T, Arai H, Kakizaki S. Balloon-occluded transcatheter arterial chemoembolization for hepatocellular carcinoma. World J Hepatol 2018;10:485-95.

36. Pung L, Ahmad M, Mueller K, Rosenberg J, Stave C, et al. The role of cone-beam CT in transcatheter arterial chemoembolization forhepatocellular carcinoma: a systematic review and meta-analysis. J Vasc IntervRadiol 2017;28:334-41.

37. Kim HC. Role of C-arm cone-beam CT in chemoembolization for hepatocellular carcinoma. Korean J Radiol 2015;16:114-24.

38. Loffroy R, Favelier S, Cherblanc V, Estivalet L. C-arm dual-phase cone-beam CT: a revolutionary real-time imaging modality to assess drug-eluting beads TACE success in liver cancer patients. Quant Imaging Med Surg 2013;3:196-9.

39. Ford J. Transradial approach for interventional oncology: an interview with Darren Klass, MD. Intervent Oncol 360. 2016;4:E55-60. Available from https://www.iolearning.com/article/transradial-approach-interventional-oncology-interview-darren-klass-md [Last accessed on 31 Dec 2019]

40. Valgimigli M, Gagnor A, Calabró P, Frigoli E, Leonardi S, et al.; MATRIX Investigators. Radial versus femoral access in patients with acute coronary syndromes undergoing invasive management: a randomised multicentre trial. Lancet 2015;385:2465-76.

41. Chen O, Goel S, Acholonu M, Kulbak G, Verma S, et al. Comparison of standard catheters versus radial artery-specific catheter in patients whounderwent coronary angiography through transradial access. Am J Cardiol 2016;118:357-61.

42. Chen YP, Zhang JL, Zou Y, Wu YL. Recent advances on polymeric beads or hydrogels as embolization agents for improved transcatheter arterial chemoembolization (TACE). Front Chem 2019;7:408. 